\title{
Representações sociais do envelhecimento, cuidado e saúde do idoso para estudantes e profissionais de enfermagem
}

\author{
Kacciana C. Schaffer ${ }^{\star}$, Felipe Biasus ${ }^{* *}$
}

\section{Resumo}

Este artigo é resultado de um trabalho cujo objetivo foi aprofundar os conhecimentos a respeito da compreensão de estudantes e profissionais de enfermagem em relação a representação social do envelhecimento, cuidado e saúde do idoso, com o intuito de comparar diferenças das representações de estudantes e profissionais de enfermagem. O estudo seguiu um delineamento estruturado com base qualitativa, exploratória e descritiva. Fizeram parte da amostra 20 estudantes de enfermagem e 13 enfermeiros que residem na cidade de Erechim - RS. Os dados foram coletados por meio de um questionário autoaplicado, com questões abertas e fechadas, tendo sido a análise realizada a partir do software $\mathrm{EVOC}^{\circledR}$. $\mathrm{Na}$ análise dos dados, não foram identificadas diferenças significativas nas representações sociais dos participantes para os diversos objetos de representação estudados. As diferenciações, nas teorias leigas elaboradas, podem estar relacionadas com a experiência do trabalho profissional.

Palavras-chave: Envelhecimento. Enfermagem. Saúde do idoso. Representações sociais.

\section{Introdução}

A partir da literatura científica, observa-se que o processo de envelhecimento populacional vem acontecendo de forma generalizada em todo o mundo, e mais especificamente, segundo Costa e Borges (2005), o crescimento da população idosa (pessoas com 60 anos ou mais de idade) tem se acentuado nas diferentes regiões menos desenvolvidas do planeta, o que levará, possivelmente, no ano de 2025, a que a maioria das populações de idosos, em números absolutos, pertença ao terceiro mundo.

Tendo em vista as estimativas apresentadas, constata-se a importância do estudo do envelhecimento na atualidade. Nesse sentido, a Ciência do Envelhecimento é uma área que permite refletir acerca do processo em todos os seus campos de atuação e construção de saber, e a Gerontologia é uma disciplina científica multi e interdisciplinar, cujas

* Enfermeira. Especialista em Gerontologia - URI Campus de Erechim. Endereço para correspondência: Rua Paraná, 57, apto. 92, Centro, CEP: 99700-000, Erechim - RS. E-mail: k_acci@hotmail.com.

** Psicólogo. Mestre em Psicologia - UFSC. Professor do curso de Psicologia da URI - Campus de Erechim.

$\hookrightarrow$ doi:10.5335/rbceh.2012.049 
finalidades são estudos voltados para as pessoas idosas, as características do envelhecer enquanto fase final do ciclo de vida e seus determinantes biopsicossociais. (FAZZIO, 2012).

De acordo com Cachioni e Neri (2004), a gerontologia é um amplo campo profissional e disciplinar, do qual faz parte a educação gerontológica. Esta também se ocupa da educação dos idosos e da formação de profissionais para essa prática. Em nosso país, a construção da educação nessa área avança, principalmente, a partir da atuação de cursos de pós-graduação em gerontologia, ação fortalecida pela criação de universidades da terceira idade, importante locus de programas para idosos, de pesquisa e de formação de recursos humanos, embora nelas ainda predominem ações pedagógicas não especializadas.

Segundo Lima, Silva e Galhardoni (2008), o processo de envelhecimento e a velhice são temas discutidos indissociavelmente, por tratarem-se de esferas complementares do conhecimento. Entretanto, é correto considerar o envelhecimento como um processo implicado por normatizações intraindividuais e interindividuais. Nesse segundo ponto, ele segue uma construção sócio-histórica, e ambos estão marcados por variáveis como acesso a oportunidades educacionais, adoção de cuidados em saúde e realização de ações que acompanham $o$ curso de vida. Nesse sentido, enquanto o envelhecimento define-se como processo, a fase da velhice caracteriza-se pelo estado de "ser velho", que, por sua vez, está implicado com o - ou é resultado do - processo de envelhecimento, e ambos acontecem dentro de contextos sociais, políticos e individuais diversos.

Conforme Martins, Camargo e Biasus (2009), a velhice está associada à qualidade de vida e à saúde, ressaltando-se que a saúde, nessa fase da vida, relaciona-se com autonomia e independência. Portanto, a falta de saúde é uma questão determinante de qualidade de vida negativa. Para determinar a qualidade de vida positiva, além da saúde, outros fatores, como atividade, renda, estilo de vida, religião e família, são fundamentais.

Vários autores (BRÊTAS; OLIVEIRA, 1999; KUNHEN et al., 2005; FRANCHI; MONTENEGRO JÚNIOR, 2005) destacam que o envelhecimento é marcado por dinamicidade e progressividade, sendo um processo durante o qual ocorrem mudanças morfológicas, funcionais, bioquímicas e psicológicas que inscrevem progressiva perda da capacidade de adaptação da pessoa ao meio ambiente, provocando maior vulnerabilidade e incidência de processos patológicos.

Biasus, Demantova e Camargo (2011) evidenciam que envelhecer é uma passagem natural e universal. Porém, a classificação do processo em categorias específicas depende de fatores econômicos, históricos, sociais, de políticas e de ideologias, assim como de aspectos simbólicos e culturais, com suas crenças, seus valores e suas tradições, o que proporciona uma variabilidade nas formas de conceber e criar modelos de vida para o envelhecimento.

De acordo com Whitaker (2007), se perguntarem para os idosos sobre o que 
pensam do processo do envelhecimento diante da sociedade, certamente cada um falará de suas experiências, as quais vão se acumulando em sua memória, que, seletiva, pode eventualmente rejeitar as mais dolorosas.

Segundo Martins, Camargo e Biasus, "o termo idoso comporta certa ambiguidade, pois ele aparece associado tanto a aspectos positivos como negativos" (2009, p. 839), contudo, prevalece a visão de atividade, autonomia. Ainda, os autores acrescentam que a ideia de velho é de alguém que se enxerga como velho e dessa maneira não se cuida, entregando-se à monotonia e apresentando um desânimo maior.

Diante do exposto, fica claro que faz parte do envelhecimento a presença de algumas perdas e morbidades para 0 idoso. Nesse sentido, Ramos e Toniolo (2005) referem que os idosos, em sua maioria, desenvolvem muitas morbidades crônicas: $80 \%$ deles têm pelo menos uma doença crônica, e cerca de $15 \%$, pelo menos 15 doenças crônicas não transmissíveis. De acordo com os mesmos autores, com o aumento da expectativa de vida em todo o mundo, observa-se uma maior incidência e prevalência das doenças cardiovasculares. A prevalência da hipertensão arterial sistêmica (HAS) e das doenças cardiovasculares tende a aumentar, cada vez mais, devido às mudanças que ocorrem no organismo ao envelhecer.

Andrade (2003) destaca que o processo de saúde-doença revela uma relação que ultrapassa o corpo individual e social, confrontando-se com as turbulências do ser humano enquanto ser total. Trata- -se de um fenômeno clínico e sociológico vivido culturalmente, e, assim, importa tanto por seus efeitos no corpo, como por suas repercussões no imaginário. Nessa perspectiva, a saúde - ou seu contrário, a doença - é um fenômeno tanto individual como social, marcado num tempo e espaço histórico e cultural.

Esta pesquisa teve por objetivo compreender as representações sociais a respeito do envelhecimento, cuidado do idoso e idoso saudável e comparar as ideias dos estudantes de enfermagem e profissionais da mesma área. Parte do pressuposto teórico das representações sociais como construtos socialmente elaborados e partilhados. Tais cognições sociais implicam no comportamento, como sugerem Moscovici (1978), Jodelet, (2001) e Vala (1996). Diante disso, percebe-se que essa teoria, ao subsidiar a investigação do fenômeno das representações sociais - neste caso, de objetos como envelhecimento, cuidado do idoso e idoso saudável -, auxiliam na compreensão destes e na repercussão comportamental da categoria profissional estudada.

\section{Metodologia}

Este estudo foi aprovado pelo Comitê de Ética em Pesquisa da URI - Campus de Erechim, conforme resolução CNS 196/1996, sob registro 001/PHG/11. A coleta de dados ocorreu entre os meses de março e abril de 2011, em uma universidade da região Norte do estado do Rio Grande do Sul e em hospitais da mesma cidade. O estudo foi autorizado pela coordenação do curso de Enfermagem e 
pelos diretores dos hospitais em que os enfermeiros trabalhavam, consentindo a publicação dos dados oriundos da investigação.

Fizeram parte da amostra 20 alunos do curso de Enfermagem que frequentavam até o terceiro semestre, sendo $97 \%$ do sexo feminino, estes na faixa etária de 18 a 25 anos, e 13 profissionais enfermeiros, dos quais $99 \%$ eram do sexo feminino com, no mínimo, dois anos de exercício profissional. Inicialmente, buscou-se o mesmo número de participantes em cada grupo, entretanto, alguns questionários não retornaram. Dessa forma, realizamos o estudo com grupos não pareados em relação ao número de participantes.

Os dados foram coletados a partir de um questionário autoaplicado e anônimo composto de questões abertas e fechadas. A devolução do questionário respondido significou o consentimento da participação no estudo, uma vez que este dispensou a utilização do TCLE. A primeira parte do instrumento diz respeito ao teste de evocação de palavras, que consiste em solicitar que um indivíduo reproduza (verbalmente ou por escrito) o maior número, ou um número pré-determinado de termos associados a termos indutores, seguindo-se a hierarquização dos termos produzidos da maior para a menor importância. Os termos indutores para os testes de evocação foram: a) envelhecimento; b) cuidado do idoso; c) idoso saudável. A segunda parte do instrumento refere-se à caracterização dos participantes.

\section{Análise e discussão dos resultados}

Os dados coletados por meio da evocação de palavras foram analisados com auxílio do software EVOC@ (Ensembles de Programmes Permettant l'Analyse des Evocations), versão 2000. (VERGÈS; SCANO; JUNIQUE, 2002). Para tanto, o corpus de análise foi preparado no software Microsoft Exce ${ }^{\circledR}$, no qual cada linha da tabela correspondeu a um participante da pesquisa, e as colunas, às palavras evocadas, sendo colocadas em ordem de importância conforme indicações feitas pelos sujeitos. Esse corpus foi, então, submetido ao tratamento no software EVOC 2000. Neste estudo, foram analisados três corpora, um para cada termo indutor. Os dados de caracterização foram analisados com aplicação de estatísticas descritivas.

\section{Resultados e discussão}

Os estudantes que participaram pertencem a uma faixa etária de 18 a 25 anos, estando dez cursando o primeiro semestre do curso de Enfermagem e dez, o terceiro semestre. Desses estudantes, apenas seis ainda não haviam tido contato com essa faixa etária, enquanto os demais já haviam convivido com ou cuidado de idosos. No caso dos treze enfermeiros que participaram da pesquisa, a faixa etária foi de 22 a 46 anos de idade, tendo a maioria se formado entre 2002 e 2009, todos com contato direto com idosos.

Os resultados serão apresentados de acordo com cada termo indutor das evocações para cada grupo pesquisado, de modo que se possa apresentá-los e discuti-los. 
Na Tabela 1, podemos ver as evocações dos estudantes de enfermagem para o termo indutor "envelhecimento". Ela apresenta os quadrantes organizados em dois eixos: o eixo vertical corresponde à frequência de evocação das palavras e o eixo horizontal, à ordem média de evocações. Obtiveram-se 100 palavras nas evocações, sendo 62 diferentes e uma média de, aproximadamente, duas evocações por categoria semântica.

O quadrante superior esquerdo é composto pelos elementos considerados como provavelmente centrais da representação em que as frequências são maiores e mais prontamente evocados. Os elementos do quadrante superior direito e inferior esquerdo referem-se à periferia próxima. São designados dessa forma porque consistem em cognições que estabelecem relação de proximidade com o núcleo central da representação. Os elementos do quadrante inferior direito compõem o sistema periférico da representação.

Tabela 1 - Representação social estrutural de "envelhecimento" para estudantes de Enfermagem.

\begin{tabular}{|c|c|c|c|c|c|c|}
\hline & \multicolumn{3}{|c|}{$\mathrm{OME}<2,5$} & \multicolumn{3}{|c|}{$\mathrm{OME} \geq 2,5$} \\
\hline & Elemento & $f$ & OME & Elemento & $f$ & OME \\
\hline \multirow{3}{*}{$f \geq 4$} & \multirow{3}{*}{$\begin{array}{l}\text { Experiência } \\
\text { Idade }\end{array}$} & \multirow{3}{*}{$\begin{array}{l}5 \\
4\end{array}$} & \multirow{3}{*}{$\begin{array}{l}1,4 \\
2,2\end{array}$} & \multirow{3}{*}{$\begin{array}{l}\text { Cuidado } \\
\text { Dificuldade } \\
\text { Doença }\end{array}$} & 5 & 2,8 \\
\hline & & & & & 4 & 3,0 \\
\hline & & & & & 9 & 2,8 \\
\hline & \multirow[t]{11}{*}{ Dor } & 3 & 2,3 & Abandono & 2 & 3,5 \\
\hline & & & & Cabelos brancos & 3 & 2,6 \\
\hline & & & & Carência & 3 & 3,0 \\
\hline & & & & Descanso & 2 & 2,5 \\
\hline & & & & Esquecimento & 2 & 4,0 \\
\hline \multirow[t]{6}{*}{$f<4$} & & & & Felicidade & 2 & 4,0 \\
\hline & & & & Paciência & 2 & 4,0 \\
\hline & & & & Preocupação & 2 & 4,0 \\
\hline & & & & Sabedoria & 2 & 3,0 \\
\hline & & & & Saúde & 2 & 2,6 \\
\hline & & & & Tempo & 2 & 3,0 \\
\hline
\end{tabular}

A partir da análise lexicográfica, pode-se observar que a representação social do envelhecimento dos estudantes é composta pelos seguintes elementos organizadores: experiência, idade, sendo esses os elementos localizados no primeiro quadrante (quadrante superior esquerdo) da Tabela 1, com maior frequência e com evocações mais prontamente enunciadas. No quadrante superior direito, o qual aponta evocações com grande frequência e elementos menos prontamente evocados, apresentam-se os lexos cuidado, dificuldade e doença. 
Já o quadrante inferior esquerdo contém apenas uma evocação, referente a palavras de baixa frequência, porém de pronta evocação, e neste caso correspondente à palavra dor. Por fim, o quadrante inferior direito aponta pouca frequência e léxicos menos prontamente evocados, abandono, cabelos brancos, carência, descanso, esquecimento, felicidade, paciência, preocupação, sabedoria, saúde e tempo.

Ao analisar-se esses elementos, pode-se verificar o quanto os estudantes percebem o envelhecimento não como o processo descrito pela ciência, mas, sobretudo, como o resultado desse processo, designando a fase da velhice. Sua representação articula-se em torno da experiência que o idoso adquire com o passar do tempo. Aspectos relacionados à decrepitude, às perdas e ao sofrimento em envelhecer estão presentes na teoria leiga dos estudantes, o que parece fazê-los pensar que, para estar próximo de um idoso, é necessário ter paciência. É possível perceber, ainda, que os estudantes, ao destacarem mais características negativas do envelhecimento, marcam seus aspectos positivos pelos termos felicidade e sabedoria.

Esses achados estão de acordo com a pesquisa realizada por Andrade (2003), que se refere ao bem-estar quando existe um equilíbrio harmônico entre o ser humano e o seu meio. Qualquer fato que interfira de modo negativo nessa relação causa desequilíbrio e, portanto, surge o que se pode denominar de doença.

Freire Junior e Tavares conceituam de forma ampla a saúde, incorporando, nessa definição, a felicidade e o ambien- te: "Saúde significa bem-estar e felicidade: ela própria, explicitamente ou no 'silêncio do corpo' é a linguagem preferida de harmonia e equilíbrio entre o indivíduo, a sociedade e o ecossistema". (2005, p. 150).

Na visão de Pizzolato et al. (2007), o desenvolvimento é vivenciado de diferentes formas, o que acarreta diferentes maneiras de envelhecer. Diante disso, é possível considerar que a diferença de um velho ativo para um velho inativo depende de um conjunto de variáveis, como a classe social em que está inserido, a representatividade que tem nos meios de comunicação, a velocidade com que cada um envelhece - seja lenta ou rapidamente - e a repercussão social desse processo, em geral, visto como algo ruim pela sociedade, pelo fato de a mídia supervalorizar a aparência jovial.

Seguindo a descrição lexicográfica da representação social do envelhecimento dos enfermeiros, observa-se a composição representacional com base nos seguintes elementos: experiência e limitação localizam-se no quadrante superior esquerdo da Tabela 2, com maior frequência e com evocações mais prontamente enunciadas. O quadrante superior direito da mesma tabela apresenta evocações com menos frequência e elementos menos evocados, que são abandono e medo. E, finalizando, o quadrante inferior direito indica pouca frequência de evocações menos prontamente evocadas para os léxicos carência, conhecimento, cuidado, dependência, desrespeito, doença, falta de atenção e sabedoria. 
Tabela 2 - Representação social estrutural de "envelhecimento" para profissionais de Enfermagem.

\begin{tabular}{|c|c|c|c|c|c|c|}
\hline & \multicolumn{3}{|c|}{ OME $<2,5$} & \multicolumn{3}{|c|}{$\mathrm{OME} \geq 2,5$} \\
\hline & Elemento & $f$ & OME & Elemento & $f$ & OME \\
\hline \multirow{2}{*}{$f \geq 3$} & Experiência & 5 & 2,0 & Abandono & 3 & 3,0 \\
\hline & Limitação & 3 & 2,3 & Medo & 3 & 3,3 \\
\hline \multirow{8}{*}{$f<3$} & & & & Carência & 2 & 3,0 \\
\hline & & & & Conhecimento & 2 & 2,5 \\
\hline & & & & Cuidado & 2 & 3,0 \\
\hline & & & & Dependência & 2 & 3,5 \\
\hline & & & & Desrespeito & 2 & 5,0 \\
\hline & & & & Doença & 2 & 3,0 \\
\hline & & & & Falta de atenção & 2 & 5,0 \\
\hline & & & & Sabedoria & 2 & 3,5 \\
\hline
\end{tabular}

Analisando esses elementos, pode-se observar como os enfermeiros estruturam suas teorias leigas sobre o envelhecimento. No centro, surgem as ideias de experiência e limitação, de forma que $o$ envelhecimento evidencia a experiência adquirida com a passagem do tempo e, também, a existência de limitações em razão dessa temporalidade. $\mathrm{O}$ sistema periférico apresenta léxicos com significado negativo associado ao termo envelhecimento, no terceiro e quarto quadrantes da Tabela 2, quando ganha destaque o abandono que sente o sujeito que envelhece. Como os estudantes, os profissionais, ao tratarem do processo, vinculam-no à fase do desenvolvimento, parecendo não haver diferença entre o processo de envelhecimento e a fase da velhice. Esse achado está de acordo com o estudo de Biasus (2009), quando pesquisa a representação social de envelhecimento para idosos.

Ao que parece, os profissionais pesquisados percebem o envelhecimento como um processo ambivalente, ou seja, com pontos positivos e negativos. Entretanto, as cognições principais aglutinam-se em torno de imagens negativas do processo de envelhecer, confundindo-se com a fase da velhice.

Comparativamente, não há elementos suficientes para apontar alguma diferença na forma de representar socialmente o envelhecimento, pois tanto estudantes como profissionais tratam do processo de envelhecer com uma carga negativa associada, mesclando-o à fase, ou seja, aproximando as teorias leigas de envelhecimento à velhice. Pode-se pensar, ainda, que a pertença grupal dos pesquisados, vinculada à área da saúde, tenciona-os a pensar os aspectos negativos do envelhecimento por terem um contato maior com pessoas idosas, que apresentam dificuldades e necessidade de cuidado, de forma que as doenças associadas a esse processo adquirem relevância na representação social dos participantes. Conforme Queiroz (1991), 
em seus estudos sobre representações de saúde e de doença, a definição doença, para muitos, significa um intervalo na vida da pessoa em que ela deixa, involuntariamente, de cumprir atividades, produtivas ou não, o que, invariavelmente, indica um fator negativo para a existência.

O resultado a que se chega aproxima-se do estudo de Brum, Tocantins e Silva, o qual aponta que as atitudes dos profissionais de enfermagem e estudantes em relação ao idoso são, em sua maioria, negativas: "[...] reina profunda atitude negativa em nossa sociedade frente aos envelhecidos". (2005, p. 1020). Na mesma linha, pode-se, com base nos resultados do estudo e nos pressupostos da teoria das representações sociais, afirmar que o comportamento negativo frente aos envelhecidos deve-se, em grande parte, às cognições associadas a esse processo e a essa fase da vida.
Esses achados corroboram o estudo de Pizzolato et al. (2007, p. 5), o qual apontou que, para acadêmicos, o processo de envelhecer representa o conceito de velhice que está associado à visão negativa da sociedade sobre 0 idoso como um ser sem importância, descartável, ignorado, desrespeitado, discriminado, um incômodo, dependente, frágil, sinônimo de doença, abandonado, improdutivo, desvalorizado, que não tem o seu espaço. Velho, enfim, segundo esse conceito, é uma pessoa que passa de uma determinada idade e que envelhece gradativamente.

Depois de inventariar o que estudantes e profissionais pensam sobre envelhecimento, buscou-se compreender o que eles pensam sobre idoso saudável. Na Tabela 3 , estão sistematizados os elementos evocados por estudantes, e, na Tabela 4, aqueles evocados por profissionais para o termo indutor "idoso saudável".

Tabela 3 - Representação social estrutural de “idoso saudável” para estudantes de Enfermagem.

\begin{tabular}{|c|c|c|c|c|c|c|}
\hline & \multicolumn{3}{|c|}{ OME $<2,5$} & \multicolumn{3}{|c|}{ OME $\geq 2,5$} \\
\hline & Elemento & $f$ & OME & Elemento & $f$ & OME \\
\hline \multirow{4}{*}{$f \geq 5$} & Alimentação saudável & 5 & 2,2 & \multirow{4}{*}{$\begin{array}{l}\text { Cuidado } \\
\text { Disposição }\end{array}$} & 7 & 3,0 \\
\hline & Ativo & 13 & 2,1 & & \multirow[t]{3}{*}{5} & \multirow[t]{3}{*}{3,2} \\
\hline & Felicidade & 8 & 2,2 & & & \\
\hline & Saúde & 8 & 2,0 & & & \\
\hline \multirow[t]{7}{*}{$f<5$} & Alegre & 4 & 1,7 & Amigos & 2 & 3,0 \\
\hline & & & & Amor Carinho & 4 & 2,5 \\
\hline & & & & Envolvimento & 2 & 3,0 \\
\hline & & & & Família & 2 & 3,5 \\
\hline & & & & & 3 & 5,0 \\
\hline & & & & Higiene & 3 & 3,0 \\
\hline & & & & Passeio & 4 & 2,7 \\
\hline
\end{tabular}


A partir da análise lexicográfica, observa-se que a representação social dos estudantes para idoso saudável é estruturada pelos seguintes elementos organizadores: alimentação, ativo, felicidade e saúde, sendo esses os elementos localizados no primeiro quadrante (quadrante superior esquerdo) da Tabela 3, com maior frequência e com evocações mais prontamente enunciadas. No quadrante superior direito, o qual aponta evocações com grande frequência e elementos menos prontamente evocados, aparecem as palavras cuidado e disposição.

Já o quadrante inferior esquerdo contém somente uma evocação, referente a palavras de baixa frequência, porém de pronta evocação, neste caso, correspondente ao léxico alegre. Por fim, o quadrante inferior direito aponta léxicos de baixa frequência e mais prontamente evocados: amigos, amor, carinho, envolvimento, família, higiene e passeio.

Analisando-se esses elementos, verifica-se que os estudantes elaboram teorias leigas, ao tratarem de idoso saudável como um sujeito que depende de algumas condições para assim caracterizar-se, sobretudo, ter saúde, alimentar-se adequadamente, sendo ativo e mantendo-se feliz. É interessante notar que essa avaliação foi feita pelos mesmos estudantes que anteriormente salientaram os aspectos negativos do envelhecimento. Nesse novo objeto de representação, surge uma categoria de idosos que não necessariamente corresponde àquela dos que passaram pelo processo de envelhecimento descrito anteriormente.
Vale ressaltar, ainda, que a condição de idoso saudável depende, segundo os participantes, quase exclusivamente de comportamentos do próprio ser que envelhece, não se levando em consideração as interações sociais, ou as redes sociais dos idosos como aspectos importantes para esse fim.

Essas reflexões estão de acordo com Mancia, Portela e Viecili (2008), quando destacam que o envelhecimento biológico acontece de forma gradual e natural, devendo ser visto como um método evolutivo. Todos os sistemas importantes do organismo são atingidos pelo envelhecimento, contudo, tratam-se de alterações normais, e não de sinais de doença. As mudanças morfológicas e estruturais estão acompanhadas do comprometimento funcional do organismo, com variação em cada indivíduo. Segundo os mesmos autores, o estilo de vida da pessoa é o fator decisivo quando se fala de longevidade com qualidade de vida. Para que a velhice seja um período agradável, deve-se fazer um planejamento que contemple cuidados com a própria saúde ao longo de toda a existência, otimizando, assim, os anos vividos.

Por sua vez, os profissionais de enfermagem, ao tratarem do termo "idoso saudável", expõem a mesma representação, entretanto, aparece com um pouco mais de força a rede de relacionamento do idoso como um componente importante para que ele seja saudável, como demonstra a Tabela 4. 
Tabela 4 - Representação social estrutural de “idoso saudável” para profissionais de enfermagem.

\begin{tabular}{|c|c|c|c|c|c|c|}
\hline & \multicolumn{3}{|c|}{$\mathrm{OME}<2,5$} & \multicolumn{3}{|c|}{$\mathrm{OME} \geq 2,5$} \\
\hline & Elemento & $f$ & OME & Elemento & $f$ & OME \\
\hline \multirow[t]{5}{*}{$f \geq 4$} & Alimentação saudável & 4 & 1,7 & Cuidado & 4 & 3,7 \\
\hline & Saúde & 4 & 2,0 & Exercício & 4 & 3,2 \\
\hline & & & & Família & 6 & 3,3 \\
\hline & Alegria & 4 & 1,0 & Amizade & 2 & 4,0 \\
\hline & Atividade & 3 & 2,3 & Amor & 5 & 3,5 \\
\hline \multirow[t]{2}{*}{$f<4$} & Feliz & 3 & 2,0 & Convívio & 2 & 3,0 \\
\hline & Grupo & 2 & 1,5 & Lazer & 2 & 3,0 \\
\hline
\end{tabular}

$\mathrm{Na}$ evocação de estudantes e profissionais, não figuram elementos que indiquem problemas para o idoso saudável. Isso evidencia que, de certa forma, esse ideal, conforme os dois grupos da pesquisa, é bastante difícil de ser alcançado pelo sujeito que envelhece.

Ramos e Toniolo (2005) apontam que o envelhecimento saudável, de acordo com essa nova visão, é resultante da interação multidimensional entre saúde física, saúde mental, independência na vida diária, relação social, independência econômica e suporte familiar. A perda de um ente querido, a falência econômica, uma doença incapacitante, um distúrbio mental, um acidente são acontecimentos do dia a dia que podem, juntos ou isoladamente, comprometer a capacidade funcional de um indivíduo. Entretanto, o bem-estar na velhice, ou saúde num sentido amplo, seria o resultado do equilíbrio entre as várias dimensões da capacidade funcional do idoso, sem necessariamente significar ausência de problemas em todas as dimensões.

Depois de expressarem suas ideias sobre envelhecimento e idoso saudável, os participantes foram convidados a falar sobre cuidado do idoso. O intuito foi compreender as teorias leigas de estudantes de Enfermagem e enfermeiros sobre o seu principal fazer, o cuidado, aqui, especificamente, o cuidado do idoso. $\mathrm{Na}$ Tabela 5, tem-se o quadro de quatro casas do EVOC para o cuidado do idoso, a partir das evocações dos estudantes de Enfermagem. 
Tabela 5 - Representação social estrutural de "cuidado do idoso" para estudantes de Enfermagem.

\begin{tabular}{|c|c|c|c|c|c|c|}
\hline & \multicolumn{3}{|c|}{ OME $<2,5$} & \multicolumn{3}{|c|}{ OME $\geq 2,5$} \\
\hline & Elemento & $f$ & OME & Elemento & $f$ & OME \\
\hline \multirow{4}{*}{$\mathrm{f} \geq 4$} & Amor & 12 & 2,7 & Cuidado & 4 & 3,2 \\
\hline & Atenção & 9 & 2,4 & Dedicação & 4 & 3,0 \\
\hline & Carinho & 13 & 2,2 & & & \\
\hline & Paciência & 10 & 2,3 & & & \\
\hline \multirow[t]{6}{*}{$f<4$} & Família & 2 & 2,0 & Afeto & 3 & 2,6 \\
\hline & & & & Ajuda & 2 & 3,0 \\
\hline & & & & Amigos & 2 & 5,0 \\
\hline & & & & Compreensão & 3 & 3,3 \\
\hline & & & & Organização & 2 & 3,0 \\
\hline & & & & Responsabilidade & 3 & 3,6 \\
\hline
\end{tabular}

A partir da análise lexicográfica, pode-se observar que a representação social do cuidado do idoso apresentada pelos estudantes é composta pelos seguintes elementos organizadores: amor, atenção, carinho e paciência, sendo esses os elementos localizados no primeiro quadrante. No quadrante superior direito, em que são apontados elementos com menos frequência de evocação, contudo com maior prontidão, aparecem os elementos cuidado e dedicação. $\mathrm{O}$ quadrante inferior esquerdo contém somente uma evocação, de baixa frequência e pouco citada: o elemento família. Finalizando, o quadrante inferior direito aponta como de menor frequência e menos prontamente evocados os termos afeto, amigos, ajuda, compreensão, organização e responsabilidade.

De acordo com essa tabela, a pessoa que se propõe a cuidar de idosos precisa ter características e habilidades interpessoais, sobretudo, disponibilidade de dar carinho, atenção, paciência. Ao que parece, a teoria leiga apresentada pelos alunos segue uma ideia estereotipada de cuidado, possivelmente influenciada pelo momento do curso em que estão, bem como pelas noções socialmente elaboradas e compartilhadas sobre o idoso e o seu cuidador.

Na visão de Brum, Tocantins e Silva (2005), a finalidade da ação de cuidar deve estar desvinculada da idade cronológica e da expectativa de "recuperação" do cliente. Esse cuidar deve atender às necessidades físicas e não físicas do cliente, englobando família-ambiente-cliente-profissional, visando a apreciar a vida.

Segundo Gandolpho e Ferrari (2006), o cuidado é sempre ocupação e preocupação, não havendo possibilidade de separá-lo do ser humano, pois se trata de algo que lhe é intrínseco, faz parte da sua natureza. Tudo e todos que estão ao nosso redor necessitam de cuidado.

Por sua vez, os profissionais de enfermagem tratam do tema de maneira mais pragmática, sem muitos eufemismos, sendo o carinho um fator fundamental 
que se articula com o respeito e a qualidade do cuidado, prática desenvolvida com afeto, dedicação, responsabilidade, com vistas à saúde do idoso, conforme sistematiza a Tabela 6 .

Tabela 6 - Representação social estrutural de“cuidado do idoso" para profissionais de enfermagem.

\begin{tabular}{|c|c|c|c|c|c|c|}
\hline & \multicolumn{3}{|c|}{$\mathrm{OME}<2,5$} & \multicolumn{3}{|c|}{$\mathrm{OME} \geq 2,5$} \\
\hline & Elemento & $f$ & OME & Elemento & $f$ & OME \\
\hline$f \geq 4$ & Carinho & 5 & 2,2 & Respeito & 6 & 2,8 \\
\hline \multirow[t]{8}{*}{$f<4$} & Qualidade & 2 & 1,5 & Afeto & 2 & 2,5 \\
\hline & & & & Amor & 2 & 3,0 \\
\hline & & & & Dedicação & 3 & 3,6 \\
\hline & & & & Digno & 2 & 3,5 \\
\hline & & & & Interação & 2 & 3,0 \\
\hline & & & & Responsabilidade & 2 & 2,5 \\
\hline & & & & Saúde & 2 & 2,5 \\
\hline & & & & Solidariedade & 2 & 5,0 \\
\hline
\end{tabular}

Na visão de Silva (2010), a ação de cuidar envolve atividades de apoio, facilitação, capacitação, ajuda, atenção, troca de ideias, tomada de decisões, as quais são promotoras ou mantenedoras do bem-estar. Trata-se de uma necessidade e de um recurso do ser humano cuidar, oferecer bem-estar e primar pela boa qualidade de vida, tanto sua quanto das demais pessoas. É olhar com olhos interessados, falar com verdade e ouvir com compaixão. É, para os enfermeiros, realizar o trabalho com vontade de fazer o melhor e de obter o melhor resultado. Conforme Gandolpho e Ferrari (2006), cuidar é mais que um ato; é uma atitude de preocupação, ocupação, responsabilidade e envolvimento afetivo com o outro.

\section{Considerações finais}

Após a análise dos dados, não se percebeu diferenças acentuadas na representação social dos participantes para os diferentes objetos de representação (envelhecimento, idoso saudável e cuidado do idoso).

As sutis diferenças entre as teorias leigas elaboradas podem estar vinculadas à experiência de trabalho dos profissionais, que permite visões mais pragmáticas para o objeto "idoso saudável", ao abordarem a influência da rede de relacionamentos do idoso na conquista de uma velhice saudável. Já as teorias leigas sobre "cuidado do idoso" evidenciam uma visão prática, possivelmente pela experiência profissional, o que os estudantes elaboram num plano mais conceitual, ao que parece, influenciados pela escolha profissional e pelo momento 
do curso em que se encontram.

Além disso, a pequena variabilidade nas representações dos diferentes grupos pesquisados sugere que estar num curso de Enfermagem, ou estar trabalhando na área não implica uma influência muito grande na construção desses conceitos, sobretudo no que se refere ao objeto envelhecimento, que é representado da mesma forma que outros estudos, envolvendo outros grupos sociais e profissionais, já apontaram.

O estudo sugere ser fundamental que os cursos de formação possam discutir aspectos relacionados ao envelhecimento normal, destacando que adoecimento e algumas perdas são normais ao processo. Do mesmo modo, é importante que se conheça a forma como os profissionais representam essa fase, pois isso pode sugerir a maneira mais adequada de comportar-se diante de pessoas idosas que necessitam de cuidados.

No que se refere ao estudo da representação social de cuidado do idoso e de idoso saudável, pode-se indicar esta pesquisa como uma investigação original, na medida em que pouco material teórico foi encontrado nas bases pesquisadas. Por sua vez, quanto à representação social do envelhecimento, este estudo corrobora outros já publicados, conforme citado anteriormente.

Por fim, sugerem-se novos estudos sobre essas temáticas, com maior aprofundamento, para que se possa compreender esse fenômeno tanto do ponto de vista intraindividual, como da perspectiva interindividual, destacando-se seus aspectos sociais e suas repercussões junto aos diferentes profissionais e setores da sociedade. Da mesma forma, essas pesquisas possibilitam subsidiar informações e conhecimento para processos e programas de educação para a velhice, bem como para a preparação profissional daqueles que atuam junto a essa população.

Social representations of aging, care and health the elderly for students and professional nursing

\section{Abstract}

This article is the result of a study whose aim was to deepen the knowledge regarding the understanding of students and nurses in relation to social representation of aging, health care and the elderly, in order to compare of to representations the differences found between students and nursing professionals. The study follows a design based on structured qualitative, exploratory and descriptive. The sample consisted of 20 nursing students and 13 nurses residing in the city of Erechim - RS. Data were collected through a self-administered questionnaire with open and closed questions, with the same analysis was performed with the EVOC ${ }^{\mathrm{TM}}$ software. Withanalyzing of the data, one did not see defined differences in the social representation of the participants to the several objects of representation study. What differs in lay theories developed, may be related to the experience of professional work.

Keywords: Aging. Nursing. Elderly healthy. Social representations. 


\section{Referências}

ANDRADE, G. O. Representações sociais de saúde e de doenças na velhice. Acta Scientirum Health Sciences, Maringá, PR, v. 25, n. 2, p. 207-213, 2003.

BIASUS, F. Representação social da psicologia. In: FÓRUM NACIONAL EM SAÚDE, 2 , SALÃO CIENTÍFICO DAS CIÊNCIAS DA SAÚDE, 1, 2009, Erechim. Anais do II Fórum Nacional em Saúde - I Salão Científico das Ciências da Saúde. Erechim: Edifapes, 2009.

BIASUS, F; DEMANTOVA, A.; CAMARGO, B. V. Representações sociais do envelhecimento e da sexualidade para pessoas com mais de 50 anos. Temas em Psicologia, Ribeirão Preto, SP: Sociedade Brasileira de Psicologia, v. 19, n. 1, p. 319-336, 2011.

BRÊTAS, A. C. P.; OLIVEIRA, E. M. Interseções entre as áreas de conhecimento da gerontologia, da saúde e do trabalho: questões para reflexão. Saúde e Sociedade, São Paulo, v. 2, n. 8, p. 59-82, 1999.

BRUM, A. K. R.; TOCANTINS, F. R., SILVA, T. J. E. S. O enfermeiro como instrumento de ação no cuidar do idoso. Revista Latino-Americana de Enfermagem, Ribeirão Preto, SP, v. 13, n. 6, p. 1019-1026, nov./dez. 2005.

CACHIONI, M.; NERI, A. L. Educação e gerontologia: desafios e oportunidades. Revista Brasileira de Ciências do Envelhecimento Humano, Passo Fundo, v. 1, n. 1, p. 99-115, jan./jun. 2004.

COSTA, G. A.; BORGES, L. J. Impacto da atividade física na satisfação de vida, sentido de auto-eficácia e análise do perfil sócio-demográfico de idosos. In: GONÇALVES, K. A.; GROENVALD, F. M. R. (Orgs.). Qualidade de vida e estilo ativo no envelhecimento. Porto Alegre: Novo Tempo, 2005.

FAZZIO, D. M. G. Envelhecimento e qualidade de vida: uma abordagem nutricional e alimentar. Revista Revisa, São Paulo, v. 1, n. 1, p. 76-88, jan./jun. 2012.
FRANCHI, B. M. K.; JUNIOR, M. M. R. Atividade física: uma necessidade para a boa saúde na terceira idade. Revista Brasileira em Promoção da Saúde. Fortaleza, n. 18, 2005.

GANDOLPHO, M. A.; FERRARI, M. A. C. A enfermagem cuidando do idoso: reflexões bioéticas. O Mundo da Saúde, São Paulo, v. 30, n. 3, jul./set. 2006.

JODELET, D. Representações sociais: um domínio em expansão. In: JODELET, D. (Org.). As representações sociais. Rio de Janeiro: EdUERJ, 2001. p. 17-44.

FREIRE JUNIOR, R. C.; TAVARES, M. F. L. A saúde sob o olhar do idoso institucionalizado: conhecendo e valorizando sua opinião. INTERFACE - Comunicação, Saúde, Educação, Botucatu, SP, v. 9, n. 16, p. 147-158, fev. 2005.

KUNHEN, A. P. et al. Programa de atividade física para terceira idade do CDS/UFSC: o efeito do exercício físico na resistência muscular. Revista Eletrônica Extensão, v. 1, n. 0, 2004.

LIMA, A. M. M.; SILVA, H. S.; GALHARDONI, R. Envelhecimento bem-sucedido: trajetórias de um constructo e novas fronteiras. Interface Comunicação, Saúde, Educação, Botucatu, SP, v. 12, n. 27, out./dez. 2008.

MANCIA, J. R.; PORTELA, V. C. C.; VIECILI, R. A imagem dos acadêmicos de enfermagem acerca do próprio envelhecimento. Revista Brasileira de Enfermagem, Brasília, v. 61, n. 2, p. 221-226, 2008.

MARTINS, M. R. C.; CAMARGO, V. B.; BIASUS, F. Representações sociais dos idosos e da velhice de diferentes faixas etárias,. Univesitas Psychologics, Bogotá, Colômbia, v. 8, n. 3, p. 831-847, 2009.

MOSCOVICI, S. A representação social da psicanálise. Trad. de Álvaro Cabral. Rio de Janeiro: Jorge Zahar Editores, 1978. 
PIZZOLATO, A. C. et al. Representação social do processo do envelhecer: uma visão dos acadêmicos de enfermagem. In: Jornada Internacional, 5 e Conferência Brasileira sobre representações, 3, 2007, Brasília:Anais... Brasília, 2007.

RAMOS, L. R.; TONIOLO, J. N. Guia de medicina ambulatorial e hospitalar Unifesp - Escola Paulista de Medicina: Geriatria e Gerontologia. Barueri, SP: Manole, 2005.

SILVA, R. X. da. Qualidade de vida e sofrimento mental em trabalhadores de enfermagem. 2010. Dissertação (Mestrado) - Programa de Pós-Graduação em Ciências da Saúde, Universidade Cruzeiro do Sul, São Paulo, 2010.

VALA, J. Representações sociais: para uma psicologia social do pensamento social. In: VALA, J.; MONTEIRO, M. B. (Org.). Psicologia social. Lisboa: Fundação Calouste Gulbekian, 1996. p. 457-502.

WHITAKER, A. C. D. Envelhecimento e poder. Campinas, SP: Alínea, 2007. 